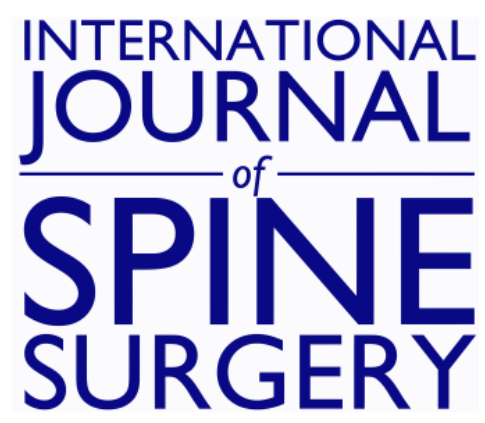

\title{
Incidence and Resolution Strategies for Early-Onset Postoperative Leg Pain Following Lumbar Total Disc Replacement
}

Richard D. Guyer, Nicole Ferko, Ashley Bonner, Aaron Situ and Donna D. Ohnmeiss

Int J Spine Surg published online 22 September 2021

http://ijssurgery.com/content/early/2021/09/20/8128

This information is current as of April 26, 2023.

Email Alerts Receive free email-alerts when new articles cite this article. Sign up at:

http://ijssurgery.com/alerts 


\title{
Incidence and Resolution Strategies for Early-Onset Postoperative Leg Pain Following Lumbar Total Disc Replacement
}

\author{
RICHARD D. GUYER, MD,${ }^{1}$ NICOLE FERKO, ${ }^{2}$ ASHLEY BONNER, ${ }^{2}$ AARON SITU, ${ }^{2}$ \\ DONNA D. OHNMEISS, PHD ${ }^{1,3}$ \\ ${ }^{I}$ Center for Disc Replacement at Texas Back Institute, Plano, Texas, ${ }^{2}$ CRG-Eversana Canada Inc, Burlington, Ontario, Canada, ${ }^{3}$ Texas Back Institute Research \\ Foundation, Plano, Texas
}

\begin{abstract}
Background: Lumbar total disc replacement (TDR) has produced results similar or superior to fusion in treating symptomatic disc degeneration. Some patients have reported onset of leg pain early after surgery. Little information is available specifically on this problem. The purpose of this study was to investigate the incidence of early-onset postoperative leg pain following lumbar TDR and to describe strategies for its treatment.

Methods: The study was based on a post hoc analysis of prospectively collected adverse event data from 283 patients in the activL Food and Drug Administration investigational device exemption study. Early-onset leg pain was defined as occurring between 0 and 4 weeks postprocedure, and the baseline visual analog scale score in the affected $\operatorname{leg}(\mathrm{s})$ was $<25$ (of 100). The treatment types these patients received were analyzed.

Results: Among 283 patients, $26(9.2 \%)$ had an early-onset leg pain event. The majority of these events resolved $(20 / 26,76.9 \%)$. Of those resolving, 55\% (11/20) did so within 3 months. Most patients received at least $1 \mathrm{drug}$ treatment for leg pain $(92.3 \%)$. Of those receiving drug therapy, the most common type was neurogenic $(61.5 \%)$, followed by narcotics $(46.2 \%)$. Steroid use was prescribed in $30.8 \%$. The majority of resolved cases were not on narcotics and resolved with neurogenic drugs. Three patients went on to have surgery, none of whom benefited from it. Age, body mass index, and baseline disability scores were predictive of time to resolution.

Conclusion: Early-onset postoperative leg pain occurred in approximately $10 \%$ of lumbar TDR patients. The majority of events resolved, often within 3 months. Treatment with conservative care, including medication(s), was more effective in resolving symptoms rather than surgery.

Clinical Relevance: This study provides useful information for providers and patients on the incidence, treatment, and resolution of leg pain with onset after lumbar TDR and not related to direct neural compression identified by imaging.
\end{abstract}

Level of Evidence: 2.

Total Disc Replacement

Keywords: total disc replacement, lumbar spine, leg pain, adverse event

\section{INTRODUCTION}

Lumbar total disc replacement (TDR) has undergone rigorous study over the past 20 years both in the United States and Europe, including Investigational Device Exemption (IDE) randomized trials. ${ }^{1-5}$ Early results from TDR studies demonstrated noninferiority to lumbar fusion, and long-term follow-up suggested a lower incidence of subsequent surgery. ${ }^{3,6}$ Certainly, as with interbody fusion to treat symptomatic disc degeneration, there is a risk of complications and adverse events (AEs) following TDR. One of the more challenging early postoperative events to evaluate is pain. This can be residual pain from the original symptoms or the onset of new symptoms related to technical aspects of the procedure, such as malpositioned implants or direct or indirect manipulation of neural tissue. Investigation of such symptoms requires careful evaluation of pain location and severity compared with preoperative complaints, time of onset, and sensation type. In the event of leg pain, this has been encountered following several lumbar interbody fusion procedures, including anterior lumbar interbody fusion. In a series of 44 anterior lumbar interbody fusion patients, there was a brief comment noting $2.3 \%$ of patients had "transient new radiculopathy", which resolved within 6 weeks. ${ }^{9}$ A 
meta-analysis found that with the transpsoas approach to lateral lumbar interbody fusion, the rate of transient symptoms in the thighs/groin was $21.7 \%{ }^{10}$ The cause for these symptoms was often attributed to psoas muscle manipulation related to this approach. In Food and Drug Administration (FDA) IDE trials, AE reports of various leg symptoms occurring within 7 weeks after TDR or fusion occurred in $10.6 \%$ to $25.0 \%$ of patients. ${ }^{11,12}$ Unfortunately, no details of these symptoms were provided, and there was no standardization of wording used in event reporting. This would have allowed investigation into whether the symptoms were new or exacerbation of preoperative symptoms; there is also the possibility of a patient being counted more than once in AE reporting of lower extremity symptoms. To the authors' knowledge, there has not been a detailed analysis of the onset of leg pain after TDR. The purpose of this study was to determine the occurrence rate of early-onset postoperative leg pain, investigate the course of its resolution, investigate treatments provided, and make recommendations for treatment of this condition.

\section{METHODS}

Institutional Review Board approval was received for each center participating in this FDA IDE trial. This study is based on post hoc analysis of data from a large randomized, multicenter trial. ${ }^{5}$ The original trial enrolled patients from 14 sites; 218 were randomly assigned to the investigational group to receive an activL artificial disc, and 106 were randomly assigned to the control group to receive either ProDisc-L (Centinel Spine, West Chester, PA) or a Charité artificial disc (Depuy Spine, Raynham, MA; not included in the current study since no longer available). The trial was registered on ClinicalTrials.gov, NCT00589797, and was approved by each center's Institutional Review Board. All patients were treated for single-level symptomatic disc degeneration unresponsive to at least 6 months of nonoperative care. Detailed study inclusion and exclusion criteria have been described previously. ${ }^{5}$

The subgroup of patients studied in detail were those who experienced early-onset postoperative leg pain. This event was defined as a leg pain AE reported to occur between 0 and 4 weeks postprocedure, with or without concomitant back pain, and located within either or both legs (i.e., "the target leg[s]"). For an event to be established as a postoperative early-onset event, the baseline visual analog scale (VAS) score in the target leg(s) needed to be no greater than 25 (of 100).

\section{Resolution of Leg Pain Event}

The resolution date of the early-onset postoperative leg pain event was captured for the analysis. Resolution was defined as the target leg VAS pain score being reduced to \pm 5 points of the score observed at baseline, and the patient needed to be pain free for at least 12 months after the resolution date. In cases where the follow-up VAS leg pain scores conflicted with the resolution date noted in the AE form, the VAS scores were used. This is because AE reports often combined both back and leg pain events, and it was sometimes uncertain which event the resolution date referred to. In rare cases, a patient's VAS leg pain score appeared low throughout the onset date to resolution time. It such cases, it is possible that the leg pain event occurred and resolved over a brief time, and this was not captured in regularly scheduled assessments. In these instances, time to resolution was assumed to be 1 day. Patients were classified as "unresolved" if there was no evidence that the target leg VAS score complied with the definition for "resolved", including cases where there was loss to follow-up and VAS pain scores were missing at later time points.

\section{Treatments}

Four general categories of treatment were assessed in this study: (1) medications (eg, narcotics, muscle relaxants, analgesics, neurogenic drugs [eg, Neurontin], nonsteroidal anti-inflammatory drugs, and steroids), (2) conservative treatments (eg, acupuncture, physiotherapy, exercise, support hose, massage, and lumbar brace), (3) injection (ie, epidural, facet joint injection, [selective] nerve root block, and facet trigger injection), and (4) surgical treatment (ie, fusion surgery). Patients could have received multiple treatment types as well as multiple treatments within any one type. Postoperative medications prescribed on the day of the procedure were not counted as treatment for the leg pain event unless there was evidence that these treatments persisted for/during the leg pain event. If a treatment was prescribed for low back pain during the timing of the leg pain event, it was assumed that this benefitted the coinciding leg pain condition. If a new treatment started/occurred after the leg pain 


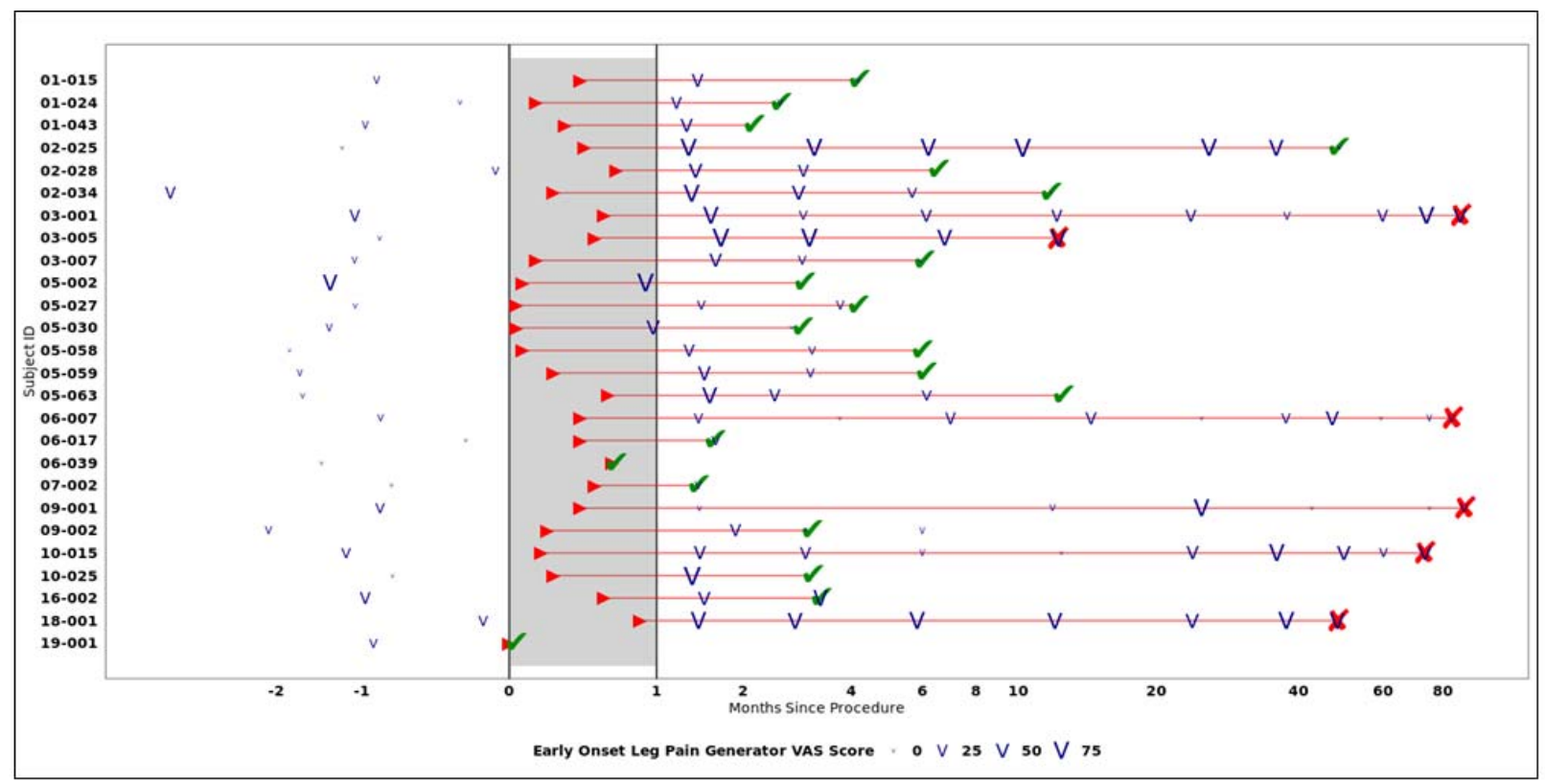

\section{- Start date of early-onset leg pain; $\checkmark$ - Resolved early-onset leg pain; $X$ - Unresolved early-onset leg pain $\mathrm{V}$ - VAS score for early-onset leg pain generator, size is the magnitude of the score Duration of early-onset leg pain - 4-week (1-month) window from procedure date used for early-onset leg pain definition}

Figure 1. Patient-level summary for timing of early-onset leg pain, resolution time, resolution status, and depiction of visual analog scale (VAS) leg pain severity over study time frame.

resolution date, this was not counted as therapy for the leg pain event. All treatments prescribed during the leg pain event were assumed to be consumed/ used unless there was evidence to the contrary.

\section{Data Collection}

Baseline variables of age, body mass index (BMI), gender, pain medication use (ie, current versus never), index level (L5-S1, L4-L5), baseline Oswestry Disability Index (ODI) scores, disc height and angle, and baseline VAS scores (back and leg), blood loss during the TDR procedure, and procedure duration were extracted. VAS leg pain scores were assessed at baseline, 6 weeks, and 3, 6, and 12 months and annually thereafter (up to 7 years, if available). Also, treatment types used for the leg pain event were retrieved from $\mathrm{AE}$ and serious adverse event reports as well as from the medications data. These data sources helped to determine time to resolution, whether the event was serious, the target leg, and the AE code/description. In some cases, a serious adverse event form was filed, from which detailed data were used to supplement information available for resolution dates, treatments, and possible confounding variables.

\section{Statistical Analysis}

Descriptive statistics were used to summarize frequency of early-onset postoperative leg pain, resolution status, leg pain location (right, left, both), classification (serious or nonserious), timing of resolution, and types of treatments provided. Categorical data were reported as frequencies and percentages. Fisher's exact tests were used to assess for differences between treatments and resolution status (categorical data). Logistic regression models were used to assess for associations between treatment combinations and likelihood of leg pain resolution, while Cox proportional hazards models were used to assess for associations between treatment combinations and time to resolution. These analyses were adjusted for baseline VAS pain severity. Univariate logistic regression analyses were conducted to assess predictors of experiencing earlyonset leg pain post-TDR. A univariate Cox proportional hazards model was used to assess predictors of resolution time. Overall, the last follow-up date was used to calculate the time to event for patients with unresolved early-onset leg pain. Statistical significance was set at $P<.05$ for all analyses. 
Table 1. Treatment types used for early-onset postoperative leg pain.

\begin{tabular}{lc}
\hline Treatment Type & \% of Patients $(\boldsymbol{n} / \boldsymbol{N})$ \\
\hline No treatment & $3.8(1 / 26)$ \\
Conservative (eg, physiotherapy) & $46.2(12 / 26)$ \\
Drug (eg, narcotic, steroid) & $92.3(24 / 26)$ \\
Injection (eg, nerve block, epidural) & $26.9(7 / 26)$ \\
Surgical (eg, fusion) & $11.5(3 / 26)$ \\
\hline
\end{tabular}

${ }^{\mathrm{a}}$ Each patient may have been given more than one treatment type.

\section{RESULTS}

Of the 283 patients, 26 patients $(9.2 \%)$ had earlyonset postoperative leg pain. Of these 26 patients, the location of the leg pain was in the left leg in 9 patients $(34.6 \%)$, right leg in $10(38.5 \%)$, and both legs in 7 patients $(26.9 \%)$. The majority of leg pain events $(73.1 \%, 19 / 26)$ were classified as nonserious. The event resolved in $76.9 \%(20 / 26)$ of patients. In 11 of the 20 patients with resolution, $55.0 \%(11 / 20)$ resolved within 3 months of onset. Figure 1 provides a summary of leg pain onset times, resolution times (if resolved), and a depiction of the VAS leg pain severity scores over time for the target leg. Among the 26 patients with post-TDR leg pain onset, $6(23.1 \%)$ had lumbar spine surgery prior to the TDR procedure. These were all discectomy and/or laminectomy.

Almost all patients, $92.3 \%$, were treated with at least 1 drug for their leg pain, 46.2\% received conservative therapy (eg, physiotherapy, massage, acupuncture, support hose), and just over one third received injection and/or surgical therapy (eg, nerve blocks, fusion, epidural, facet trigger injection). Of those receiving drug therapy, the most common type prescribed was neurogenic $(61.5 \%)$ followed by narcotics $(46.2 \%)$. The most common neurogenic drug prescribed was Lyrica, and other neurogenic drugs (eg, Neurontin) were occasionally prescribed in conjunction. Steroid use, most commonly a Medrol dose pack, was prescribed in $30.8 \%$ of cases. Analgesics were rarely used $(3.8 \%)$. For further details of the treatment categories and drug treatment types, see Tables 1 and 2.

Table 2. Drug types used for early-onset postoperative leg pain.

\begin{tabular}{lc}
\hline Drug Type $^{\mathbf{a}}$ & \% of Patients $(\boldsymbol{n} / \boldsymbol{N})$ \\
\hline None & $7.7(2 / 26)$ \\
Analgesic (eg, salicylate) & $3.8(1 / 26)$ \\
Muscle relaxant (eg, Soma) & $15.4(4 / 26)$ \\
Narcotic (eg, OxyContin) & $46.2(12 / 26)$ \\
Neurogenic (eg, Neurontin) & $61.5(16 / 26)$ \\
NSAID (eg, ibuprofen) & $30.8(8 / 26)$ \\
Steroid (eg, Medrol Dosepak) & $30.8(8 / 26)$ \\
\hline
\end{tabular}

Abbreviation: NSAID, nonsteroidal anti-inflammatory drug.

${ }^{\mathrm{a}}$ Each patient may have been given more than one drug type.
Table 3. Treatment category use by resolution status.

\begin{tabular}{|c|c|c|c|c|}
\hline $\begin{array}{l}\text { Treatment } \\
\text { Type and } \\
\text { Status } \\
\end{array}$ & $\begin{array}{c}\text { Sample by } \\
\text { Treatment } \\
\text { Status }\end{array}$ & $\begin{array}{c}\text { Not Resolved, } \\
\text { \% }(n / N) \\
n=6\end{array}$ & $\begin{array}{c}\text { Resolved, } \\
\%(n / N), \\
n=\mathbf{2 0}\end{array}$ & $P$ Value \\
\hline Conservative & & & & .365 \\
\hline No & 14 & $14.3(2 / 14)$ & $85.7(12 / 14)$ & \\
\hline Yes & 12 & $33.3(4 / 12)$ & $66.7(8 / 12)$ & \\
\hline Drug & & & & 1.00 \\
\hline No & 2 & $0.0(0 / 2)$ & $100(2 / 2)$ & \\
\hline Yes & 24 & $25.0(6 / 24)$ & $75(18 / 24)$ & \\
\hline Injection & & & & 1.00 \\
\hline No & 19 & $21.1(4 / 19)$ & $78.9(15 / 19)$ & \\
\hline Yes & 7 & $28.6(2 / 7)$ & $71.4(5 / 7)$ & \\
\hline Surgical & & & & $.008^{\mathrm{a}}$ \\
\hline No & 23 & $13.0(3 / 23)$ & $87(20 / 23)$ & \\
\hline Yes & 3 & $100(3 / 3)$ & $0.0(0 / 3)$ & \\
\hline
\end{tabular}

For conservative therapy, drugs, and injection treatment categories, there was no statistically significant association between resolution status and the presence/absence of specific treatment type (Tables 3 and 4). None of the 3 patients who underwent surgery experienced leg pain resolution. There were no statistically significant associations between drug therapy type/class and resolution status, with the exception of muscle relaxants. In this case, $86.4 \%(19 / 22)$ who were not treated with muscle relaxants resolved their leg pain $(P=.03)$. Interestingly, of those not using narcotics, $85.7 \%$ $(12 / 14)$ had leg pain resolution. Also, the majority of resolved status patients were not on narcotics $(12 / 20$ or $60 \%$ ). Interestingly, this relationship flipped with neurogenic drugs, whereby the majority of patients resolving used neurogenic drugs $(60 \%)$ versus those who did not use neurogenic drugs $(40 \%)$.

Table 4. Drug category use by resolution status.

\begin{tabular}{|c|c|c|c|c|}
\hline $\begin{array}{l}\text { Treatment } \\
\text { Type and } \\
\text { Status }\end{array}$ & $\begin{array}{c}\text { Sample by } \\
\text { Treatment } \\
\text { Status }\end{array}$ & $\begin{array}{c}\text { Not Resolved, } \\
\%(n / N) \\
(n=6)\end{array}$ & $\begin{array}{l}\text { Resolved, } \\
\%(n / N) \\
(n=20)\end{array}$ & $P$ Value \\
\hline Analgesic & & & & .23 \\
\hline No & 25 & $20(5 / 25)$ & $80(20 / 25)$ & \\
\hline Yes & 1 & $100(1 / 1)$ & $0.0(0 / 1)$ & \\
\hline Muscle relaxant & & & & .03 \\
\hline No & 22 & $13.6(3 / 22)$ & $86.4(19 / 22)$ & \\
\hline Yes & 4 & $75(3 / 4)$ & $25.0(1 / 4)$ & \\
\hline Narcotic & & & & .36 \\
\hline No & 14 & $14.3(2 / 14)$ & $85.7(12 / 14)$ & \\
\hline Yes & 12 & $33.3(4 / 12)$ & $66.7(8 / 12)$ & \\
\hline Neurogenic & & & & 1.00 \\
\hline No & 10 & $20(2 / 10)$ & $80(8 / 10)$ & \\
\hline Yes & 16 & $25(4 / 16)$ & $75(12 / 16)$ & \\
\hline NSAID & & & & .33 \\
\hline No & 18 & $16.7(3 / 18)$ & $83.3(15 / 18)$ & \\
\hline Yes & 8 & $37.5(3 / 8)$ & $62.5(5 / 8)$ & \\
\hline Steroid & & & & .33 \\
\hline No & 18 & $16.7(3 / 18)$ & $83.3(15 / 18)$ & \\
\hline Yes & 8 & $37.5(3 / 8)$ & $62.5(5 / 8)$ & \\
\hline
\end{tabular}

Abbreviation: NSAID, nonsteroidal anti-inflammatory drug. 
Table 5. Number of unique treatment types ${ }^{a}$ received and resolution status.

\begin{tabular}{lccccc}
\hline $\begin{array}{l}\text { Number of Unique } \\
\text { Treatments Received }\end{array}$ & $\begin{array}{c}\text { Sample by Number of } \\
\text { Treatments Received }\end{array}$ & $\begin{array}{c}\text { \% of Patients }(\boldsymbol{n} / \boldsymbol{N}) \text { of the } \\
\text { Total Study Sample }\end{array}$ & \% Unresolved & \% Resolved & $\begin{array}{c}\text { Odds Ratio for Association } \\
\text { (95\% CI) }\end{array}$ \\
\hline 0 & 1 & $3.8(1 / 26)$ & $0(0 / 1)$ & $100(1 / 1)$ & $0.074(0.007$ to 0.747$)$ \\
1 & 8 & $30.8(8 / 26)$ & $0(0 / 8)$ & $100(8 / 8)$ & $76.9(10 / 13)$ \\
2 & 13 & $50(13 / 26)$ & $23.1(3 / 13)$ & $75(3 / 4)$ & $25(1 / 4)$ \\
3
\end{tabular}

Abbreviation: $95 \% \mathrm{CI}, 95 \%$ confidence interval.

${ }^{\text {aT }}$ Treatment types include conservative therapy, drugs, injections, or surgeries.

Table 6. Number of unique drug types received and resolution status.

\begin{tabular}{lccccc}
\hline $\begin{array}{l}\text { Number of Unique } \\
\text { Drug Types Received }\end{array}$ & $\begin{array}{c}\text { Sample by Number of } \\
\text { Drug Types Received }\end{array}$ & $\begin{array}{c}\text { \% of Patients }(\boldsymbol{n} / \boldsymbol{N}) \text { of the } \\
\text { Total Study Sample }\end{array}$ & \% Unresolved & \% Resolved & $\begin{array}{c}\text { Odds Ratio for Association } \\
(\mathbf{9 5 \%} \text { CI) }\end{array}$ \\
\hline 0 & 2 & $7.7(2 / 26)$ & $0(0 / 2)$ & $100(2 / 2)$ & $0.32(0.12$ to 0.88$)$ \\
1 & 10 & $38.5(10 / 26)$ & $10(1 / 10)$ & $90(9 / 10)$ & \\
2 & 7 & $26.9(7 / 26)$ & $14.3(1 / 7)$ & $85.7(6 / 7)$ \\
3 & 3 & $11.5(3 / 26)$ & $33.3(1 / 3)$ & $66.7(2 / 3)$ \\
4 & 4 & $15.4(4 / 26)$ & $75(3 / 4)$ & $25(1 / 4)$ \\
\hline
\end{tabular}

Abbreviation: 95\% CI, 95\% confidence interval.

More than half of the patients were on at least 2 types of drug therapies $(53.8 \%)$ and tried at least 2 treatment types (eg, conservative and drug therapy) $(65.4 \%)$ (Tables 5 and 6). Logistic regression analyses demonstrated that the only variable significantly predicting the presence of leg pain events was baseline VAS leg pain score (ie, for the nontarget leg); the higher the baseline pain level, the greater the chance of experiencing early-onset postoperative leg pain (odds ratio $[\mathrm{OR}]=1.02$; 95\% confidence interval $[95 \% \mathrm{CI}]: 1.001$ to $1.035 ; P$ $=.038)$ (Figure 2). Additional information on the

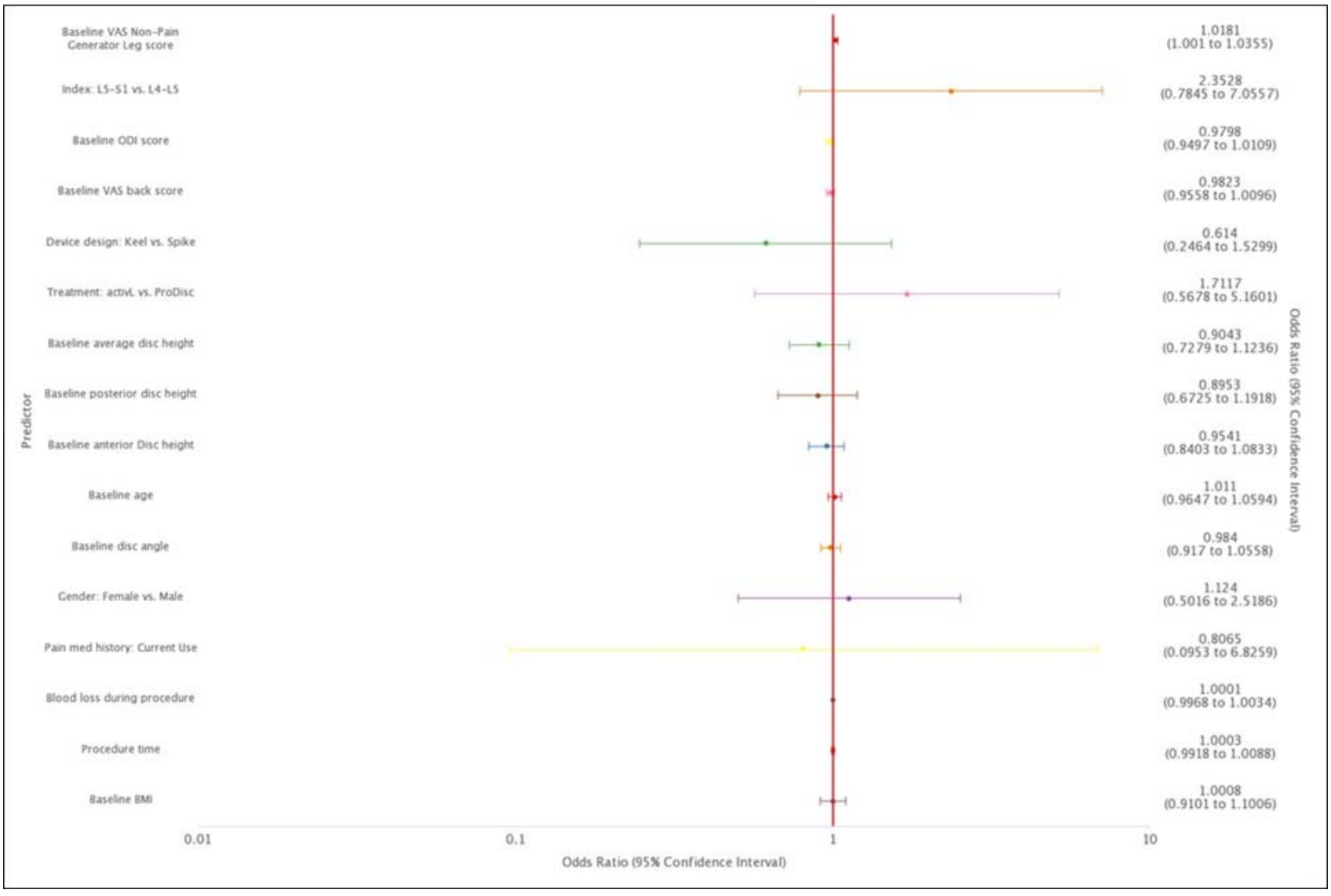

Figure 2. Logistic regression analysis results for predictors of early-onset postoperative leg pain in the total disc replacement dataset. 


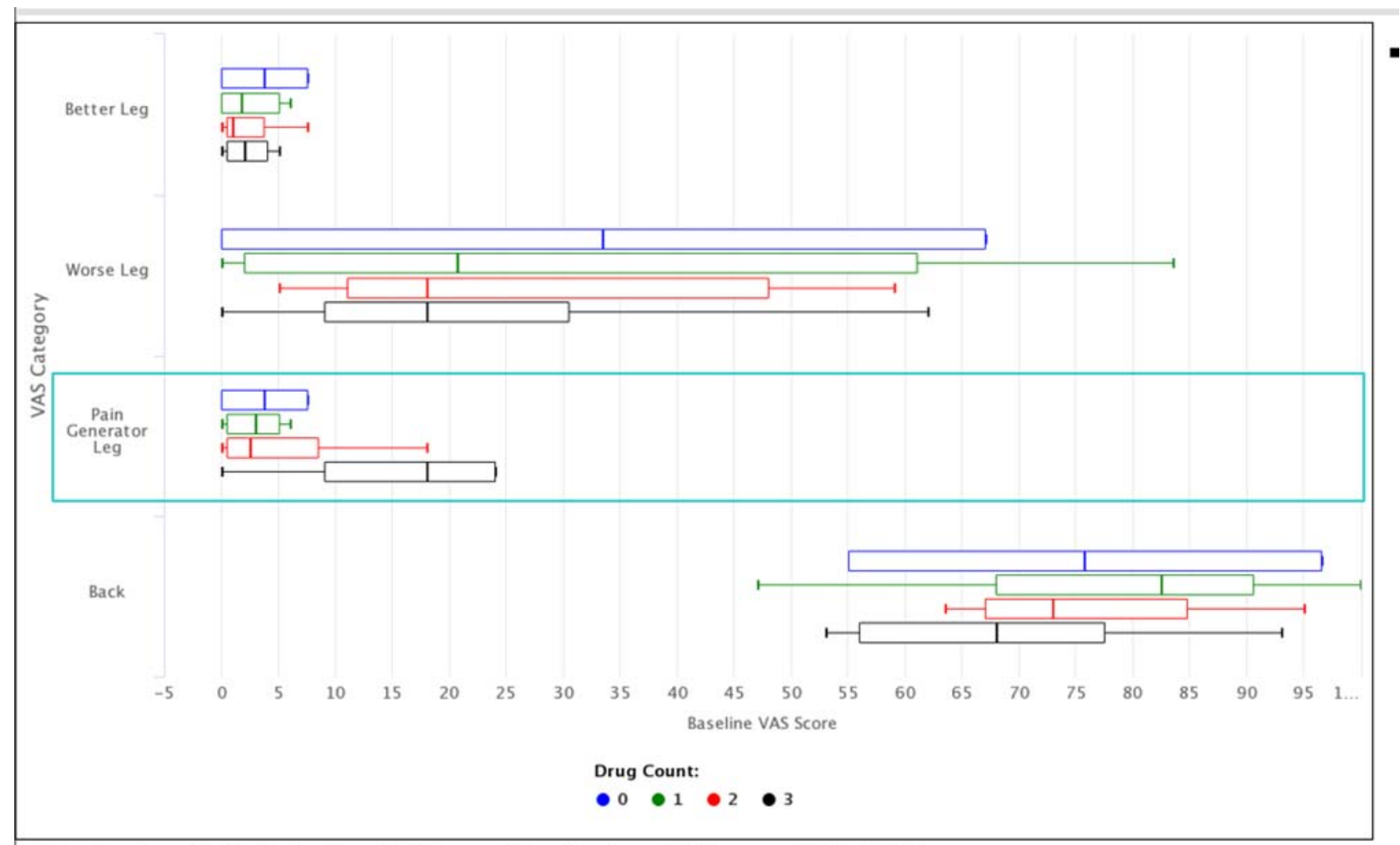

Better leg: Leg with the better (lower) VAS score; Worse leg: Leg with the worse (higher) VAS score

Pain Generator leg: Leg caused the early onset leg pain; if leg pain caused by both legs, leg with worse (higher) VAS score was used

Figure 3. Distribution of baseline visual analog scale (VAS) scores stratified by number of drug types received.

relationship between baseline VAS scores and the number of medication types received and the number of treatment types received are provided in Figures 3 and 4, respectively. When assessing only the sample of patients with early-onset postoperative leg pain events, baseline BMI $(\mathrm{OR}=0.88 ; 95 \%$ CI: 0.79 to $0.98 ; P=.02)$, baseline age $(\mathrm{OR}=0.95$; 95\% CI: 0.896 to $0.998 ; P=.04)$, and baseline Oswestry disability index score $(\mathrm{OR}=0.956 ; 95 \%$ CI: 0.915 to $0.999 ; P=.046)$ were found to be significant predictors of time to resolution. Specifically, the higher the baseline BMI, age, and disability score, the longer the time to resolution (Figure 5).

\section{DISCUSSION}

This study found that early-onset postoperative leg pain occurred in $9.2 \%$ of the TDR study population. The majority of the events were classified as nonserious and resolved within the study duration. Drug therapy and conservative treatments were commonly prescribed for the leg pain events, and just over one-third received injections including nerve blocks.

Narcotics were not necessary to resolve the postoperative leg pain events. In $85.7 \%$ of patients not taking narcotics, their leg pain resolved. Most clinicians recommend reducing or discontinuing narcotic use as early as 2 weeks after lumbar TDR surgery. ${ }^{13}$ This is consistent with concerns regarding the growing global opioid epidemic and associated mortality and morbidity impacts, including psychological addiction, physical dependence, immunological suppression, and emergency room visits. ${ }^{14-17}$ Across the entire study population, fewer than $2 \%$ of patients remained on narcotic treatment at 5 years after surgery. ${ }^{13,18}$ While most cases of earlyonset leg pain resolved with conservative therapy, some events did not resolve or took longer to do so, despite these patients generally receiving a greater number of treatments. These patients may have had a more severe case of leg pain that may be difficult to resolve and/or have a concurrent source of pain. Some of these factors were difficult to elucidate from the study given absence or inconsistencies in 


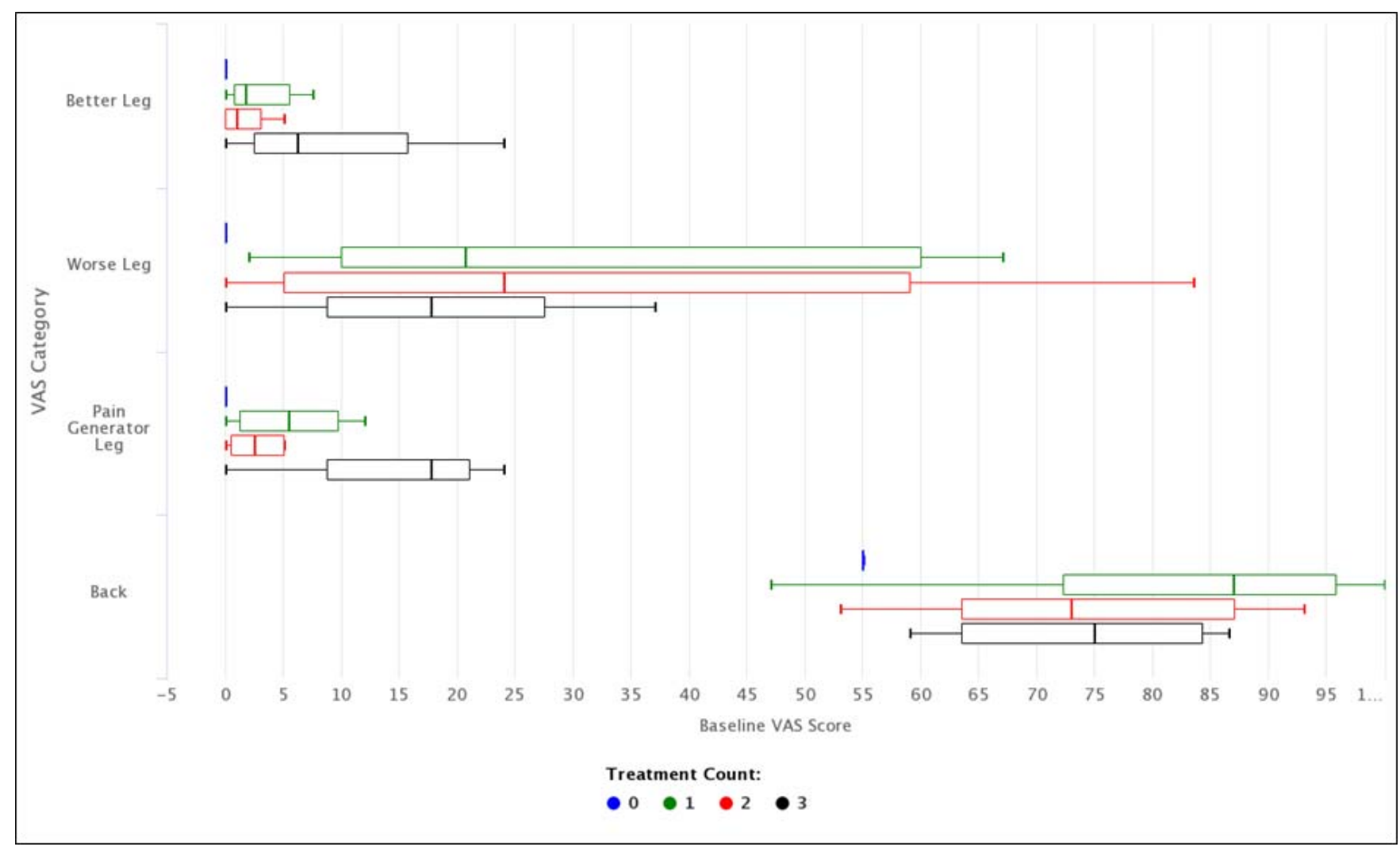

Better leg: Leg with the better (lower) VAS score; Worse leg: Leg with the worse (higher) VAS score

Pain Generator leg: Leg caused the early-onset leg pain; if leg pain caused by both legs, leg with worse (higher) VAS score was used

Figure 4. Distribution of baseline visual analog scale (VAS) scores stratified by number of treatment types (ie, drug, conservative, injection, surgery) received.

some historical, baseline, and follow-up data. Higher BMI, increased age, and higher disability scores were found to be significantly associated with a longer resolution time. The basis of the association is not clear but may be related to more severe degeneration with associated disc space collapse, greater pain sensitivity, or impact related to higher disability scores.

The cause of early-onset postoperative leg pain could not be discerned in the current study. It may be speculated that it is related to distraction of the disc space, as muscles and ligaments stretch to accommodate restored disc height and adjust to the new space. ${ }^{19}$ Such pain is rarely accompanied by neurologic deficit. It is important to differentiate the transient pain addressed in the current study from functionally debilitating continuous neuropathic pain, which may be associated with neurological deficits that are etiologically diverse, having traumatic, vascular, neoplastic, or immunological causes. ${ }^{16,20}$ Such neuropathic pain may sometimes be referred to as postlumbar surgery syndrome and may include physical trauma, psychological prob- lems, residual stenosis, synovial cysts, facet syndrome, epidural fibrosis, and more. ${ }^{16,21-23}$ There may be suspicion that the onset of leg pain after TDR surgery may be greater among patients who had undergone previous lumbar spine surgery through a mechanism of scar tissue compressing neural tissue. However, in the current study, 23.1\% of patients with new onset pain had previously undergone prior lumbar spine surgery. This was comparable to the rate of $24.5 \%$ of patients with prior lumbar surgery in the overall FDA IDE trial from which the subset of patients who were the focus of the current study were derived. ${ }^{24}$

The strength of the current study is that it was based on data collected from an IDE trial, which included a systematic assessment of AEs. This allowed for detailed analysis of the occurrence, resolution, and management of postoperative events. Despite this, there were some important limitations. The study focused on only a small subpopulation of 26 patients of the trial population, which presented restrictions for statistical analyses. Data were collected through AE reporting mecha- 


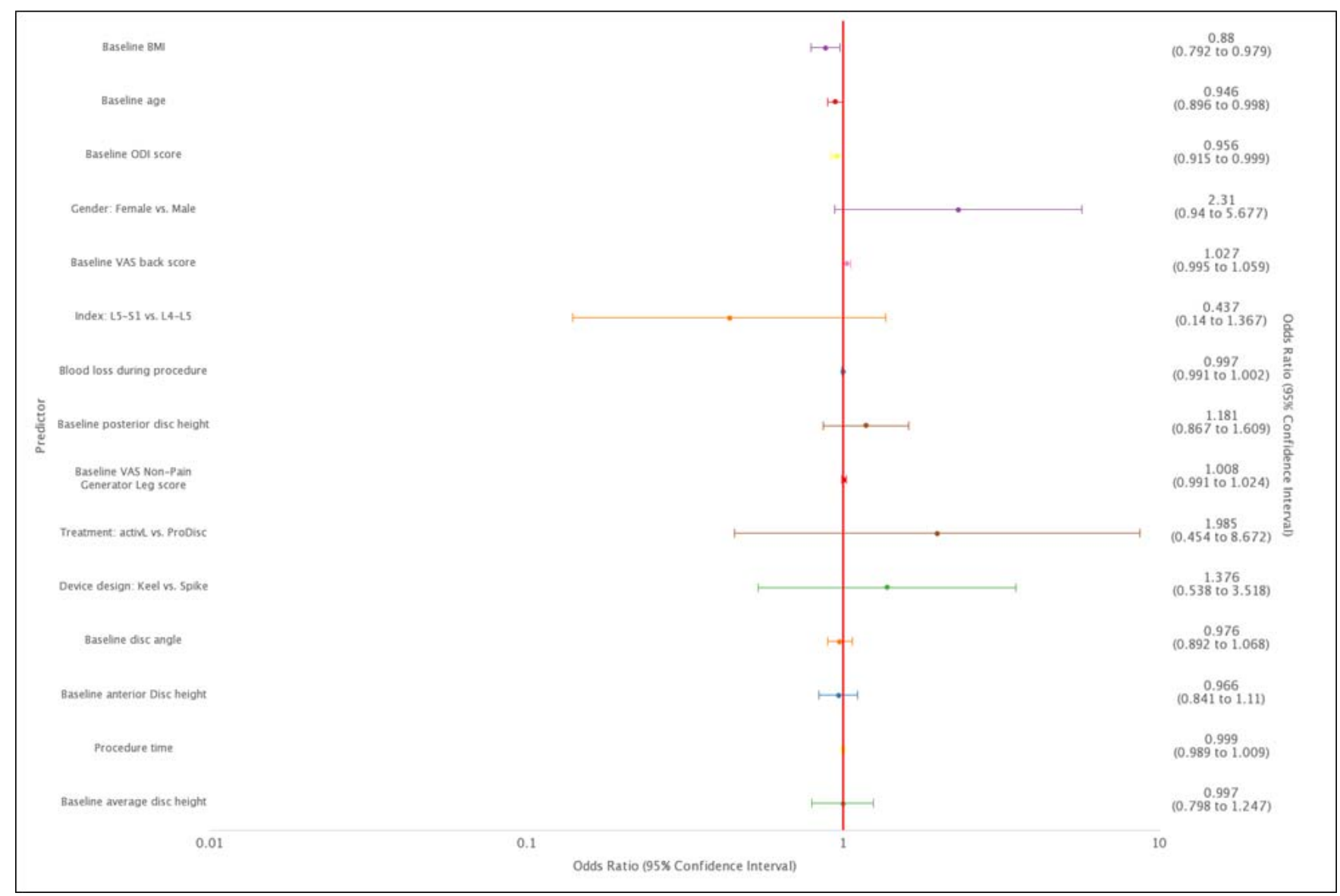

Figure 5. Logistic regression analysis results for predictors of time to resolution in early-onset leg pain patients.

nisms, which were not necessarily standardized across all sites with respect to screening of postoperative leg pain. Sometimes, treatment-specific information, such as dose, frequency, and duration of medication use, was often not reported consistently and thus could not be analyzed thoroughly. To help minimize presence of missing information or inaccuracies, all data reported in AE forms were crosschecked with data gathered from routine study follow-up visits. Finally, some inferences were required to determine resolution dates for leg pain events as this information was sometimes not clearly stipulated. We used a combination of notes reported in AE forms as well as assessment of changes in VAS leg pain score over time to help verify these assessments.

Based on experience, our clinic has developed a protocol for the diagnosis and treatment of postoperative leg pain after lumbar TDR, which bears several similarities to the findings of the current study. While the treatment regimen has not been verified in a rigorous study format, the authors thought it may provide a helpful framework for others treating patients with this condition. Patients with postoperative leg pain are first assessed for neurological deficit. If present, a computed tomography scan is obtained to rule out bony stenosis or soft tissue compression. In the absence of neurological deficit, a doppler ultrasound may be obtained if the pain is constant to rule out deep vein thrombosis. A drug therapy regimen, depending on level of pain and responsiveness, is typically administered. The majority of patients are managed with a steroid (ie, Medrol), drugs such as Lyrica and Neurontin, or a combination thereof. To manage mild or moderate pain levels when not controlled by standard analgesics, steroids may be prescribed. For more severe pain or those not responding to steroids, a dose escalation protocol may be adopted involving neurogenic drugs until pain is controlled (eg, $300 \mathrm{mg}$ of Neurontin once per day and slowly increasing to 3 times per day or a maximum of 600 mg 4 times daily). If Cymbalta is not contraindicated, it may be prescribed in conjunction with Neurontin to induce synergistic effects. In the worstcase scenario with no relief for intractable incapac- 
itating pain, a temporary spinal cord stimulator may be considered. Our protocol does not recommend posterior decompression, except in the case of unrecognized foraminal spurs documented by a computed tomography scan. As in the current study, drug types not recommended as part of our protocol, including narcotics, nonsteroidal antiinflammatory drugs, and muscle relaxants, appeared to be associated with a low probability of resolving early-onset pain.

\section{CONCLUSION}

Early-onset postoperative leg pain occurs in approximately $10 \%$ of patients following lumbar TDR. While these patients may present with clinically relevant pain, a course of medication, with or without other conservative treatment, is often recommended. Operative intervention is not recommended unless objective compression is identified, but this is extremely rare and unlikely. In the majority of patients, the new postoperative leg pain resolved within a few months. Patients with certain comorbidities, including higher BMI and age, may require a longer time to resolution.

\section{REFERENCES}

1. Blumenthal S, McAfee PC, Guyer RD, et al. A prospective, randomized, multicenter food and drug administration investigational device exemptions study of lumbar total disc replacement with the Charite artificial disc versus lumbar fusion: Part I: evaluation of clinical outcomes. Spine (Phila Pa 1976) 2005;30(14):1565-1575.

2. Gornet MF, Burkus JK, Dryer RF, et al. Lumbar disc arthroplasty versus anterior lumbar interbody fusion: 5-year outcomes for patients in the maverick disc investigational device exemption study. J Neurosurg Spine 2019;31(3):347-356.

3. Zigler JE, Delamarter RB. Five-year results of the prospective, randomized, multicenter, food and drug administration investigational device exemption study of the ProDisc-L total disc replacement versus circumferential arthrodesis for the treatment of single-level degenerative disc disease. J Neurosurg Spine 2012;17(6):493-501.

4. Guyer RD, Pettine K, Roh JS, et al. Five-year follow-up of a prospective, randomized trial comparing two lumbar total disc replacements. Spine (Phila Pa 1976) 2016;41(1):3-8.

5. Garcia R Jr, Yue JJ, Blumenthal S, et al. Lumbar total disc replacement for discogenic low back pain: two-year outcomes of the activL multicenter randomized controlled ide clinical trial. Spine 2015;40(24):1873-1881.

6. McAfee PC, Cunningham B, Holsapple G, et al. A prospective, randomized, multicenter food and drug administration investigational device exemption study of lumbar total disc replacement with the Charite artificial disc versus lumbar fusion: Part II: evaluation of radiographic outcomes and correlation of surgical technique accuracy with clinical out- comes. Spine (Phila Pa 1976) 2005;30(14):1576-1583; discussion E388-E390.

7. Zigler J, Gornet MF, Ferko N, et al. Comparison of lumbar total disc replacement with surgical spinal fusion for the treatment of single-level degenerative disc disease: a metaanalysis of 5-year outcomes from randomized controlled trials. Global Spine J 2018;8(4):413-423.

8. Ma L, Yang S, Wang H, et al. Two-and five-year followup of lumbar total disc replacement compared to fusion: a meta-analysis. Int J Clin Exp Med 2016;9:485-494.

9. Vieli M, Staartjes VE, Eversdjik HAJ, et al. Safety and efficacy of anterior lumbar interbody fusion for discogenic chronic low back pain in a short-stay setting: data from a prospective registry. Cureus 2019;11(8):e5332. doi:10.7759/ cureus.5332

10. Walker CT, Farber SH, Cole TS, et al. Complications for minimally invasive lateral interbody arthrodesis: a systematic review and meta-analysis comparing prepsoas and transpsoas approaches. J Neurosurg Spine 2019;30(4):446-460.

11. US Food and Drug Administration. Synthes Spine PRODISC-L Total Disc Replacement: Summary of Safety and Effectiveness Data (SSED); 2006. https://www. accessdata.fda.gov/cdrh_docs/pdf5/P050010B.pdf. Accessed August 23, 2021.

12. US Food and Drug Administration. CHARITÉ Artificial Disc: Summary of Safety and Effectiveness Data (SSED); 2004. https://www.accessdata.fda.gov/cdrh_docs/pdf4/ p040006b.pdf. Accessed August 23, 2021.

13. Braxton EJ, Wohlfeld BJ, Blumenthal S, et al. Postoperative care pathways following lumbar total disc replacement. Spine J 2019;44(Suppl 24):S1-S12.

14. Benyamin R, Trescot AM, Datta S, et al. Opioid complications and side effects. Pain Physician 2008;11(2 Suppl):S105-S120.

15. Nielsen RV. Adjuvant analgesics for spine surgery. Dan Med J 2018;65(3):B5468.

16. Rigoard P, Blond S, David R, et al. Pathophysiological characterisation of back pain generators in failed back surgery syndrome (Part B). Neurochirurgie 2015;61(Suppl 1):S35-S44.

17. National Academies of Sciences Engineering, and Medicine. Pain Management and the Opioid Epidemic: Balancing Societal and Individual Benefits and Risks of Prescription Opioid use. Washington DC: The National Academies Press; 2017.

18. Yue JJ, Garcia R, Blumenthal S, et al. Five-year results of a randomized controlled trial for lumbar artificial discs in single-level degenerative disc disease. Spine (Phila Pa 1976) 2019;44(24):1685-1696.

19. Strube P, Hoff EK, Schurings M, et al. Parameters influencing the outcome after total disc replacement at the lumbosacral junction. Part 2: distraction and posterior translation lead to clinical failure after a mean follow-up of 5 years. Eur Spine J 2013;22(10):2279-2287.

20. Gilron I, Baron R, Jensen T. Neuropathic pain: principles of diagnosis and treatment. Mayo Clin Proc 2015;90(4):532-545.

21. De Andrés J, Van Buyten JP. Neural modulation by stimulation. Pain Practice 2006;6(1):39-45.

22. Baber Z, Erdek MA. Failed back surgery syndrome: current perspectives. J Pain Res 2016;9:979-987.

23. Bokov A, Isrelov A, Skorodumov A, et al. An analysis of 
reasons for failed back surgery syndrome and partial results after different types of surgical lumbar nerve root decompression. Pain Physician 2011;14(6):545-557.

24. Guyer RD, Blumenthal SL, Zigler JE, et al. Impact of previous lumbar spine surgery on outcome of lumbar total disc replacement: analysis of prospective five-year follow up study data. Spine J 2019;19(9 Suppl):S106-S107.

Disclosures and COI: Richard D. Guyer: consulting (Aesculap, Orthofix, Spinal Kinetics) and royalties (Atec, Nanovis, Stryker-K2M); Nicole Ferko, Ashely Bonner, and Aaron Situ: research support/consulting, Aesculap (paid directly to employer); Donna D. Ohnmeiss: Board of Directors NASS (travel expense support received for NASS
Board of Director activities) and Texas Back Institute Research Foundation (salary).

Corresponding Author: Richard D. Guyer, MD, Center for Disc Replacement at Texas Back Institute, $6020 \mathrm{~W}$. Parker Rd. \#200, Plano, TX 75093. Phone: (972)-608-5097; Fax: (972)-608-5020; Email: rguyer@texasback.com.

Published 0 Month 2021

This manuscript is generously published free of charge by ISASS, the International Society for the Advancement of Spine Surgery. Copyright @ $\odot 2021$ ISASS. To see more or order reprints or permissions, see http://ijssurgery.com. 